\title{
El matrimonio civil como ceremonia pública especial: la clasificación de los actos oficiales.
}

\author{
Civil marriage as a public ceremony: official acts classification
}

\author{
M. ${ }^{a}$ del Carmen Portugal Bueno ${ }^{1}$ \\ Portugal.delcarmen@gmail.com
}

Recepción: 27.10.2016 Revisión: 27.12.2016 Aceptación: 27.12.2016 Publicación: 15.01.2017

\section{Resumen}

La ceremonia del matrimonio civil celebrada en los ayuntamientos ha sido considerada acto familiar o social. Sin embargo, debido al auge de estas celebraciones en dependencias municipales junto a su planificación, organización y ejecución por parte de los servicios oficiales correspondientes, se replantea la cuestión sobre su titularidad, abriendo la posibilidad de su transformación de acto privado a oficial.

Con la finalidad de dar respuesta a este planteamiento se procedió a marcar los límites de los actos oficiales a través de la revisión explorativa de diferentes expertos en la materia. $Y$ también se analizó desde el método descriptivo la realidad actual del matrimonio civil en los ayuntamientos.

El resultado obtenido con el estudio de la clasificación de los actos oficiales delimitó que los actos oficiales generales son los organizados por la Corona, el Gobierno y la Administración que tienen como objetivo conmemoraciones y acontecimientos de proyección territorial. En cuanto a los actos oficiales especiales, estos son organizados por el poder ejecutivo, legislativo y judicial con la finalidad de conmemorar o celebrar actos propios del ámbito específico de sus servicios, funciones y actividades.

Bajo esta consideración, se examinó la ceremonia de la boda civil como servicio municipal. Se determinó que el matrimonio civil celebrado en los consistorios se registra como acto privado y oficial según se produzcan unas circunstancias u otras.

\footnotetext{
${ }^{1}$ Periodista y docente
} 
Con la base de los datos obtenidos, concluimos que la ceremonia del matrimonio civil en los ayuntamientos se cataloga como acto privado o como acto oficial especial.

Palabras claves: Acto oficial, Acto oficial especial, Acto oficial general, Ceremonia, Matrimonio civil, Protocolo.

\section{Abstract}

The civil marriage ceremony performed through time in city halls has been considered as a social or familiar act. However, according to the growth of this kind of celebrations in public halls, along with their planning, organization and development by pertinent public authorities, makes necessary reconsidering the question about their ownership, letting the possibility of its transformation from a private to an official act.

In order to give an answer to this point, bounds to official acts were marked through explorative reviews made by experts. Also, the reality of civil marriages in city halls has been analysed from descriptive methods.

The obtained results by classifying official acts delimited that the general official acts were the ones organised by the Crown, the Government and the Administration, which target are commemorations and events in their territorial environments. As for the special official acts, those are the ones organised by the three powers (executive, legislative and judicial), in order to commemorate or celebrate their own acts in the specific sphere affecting their services, competencies and activities.

Under that consideration, the civil wedding ceremony has been analysed as a municipal service. Civil marriages have been determined as private or public acts according to the circumstances.

With the obtained data, we can conclude that civil marriage ceremonies carried out in city halls are catalogued as private acts or as special official acts.

Keywords: Official act, Special official act, General official act, Ceremony, Civil marriage, Protocol.

\section{Sumario}

1. Introducción

2. Metodología 


\section{Resultados}

\subsection{Clasificación de los actos oficiales del Estado}

\subsubsection{Actos oficiales de carácter general}

\subsubsection{Actos oficiales de carácter especial}

\subsection{El matrimonio civil}

4. Discusión y conclusiones

5. Referencias

\section{Summary}

1. Introduction

2. Methodology

3. Results

\subsection{National official acts classification}

\subsubsection{General official acts}

\subsubsection{Special official acts}

\subsection{Civil marriage}

4. Discussion and conclusions

\section{References}

\section{INTRODUCCIÓN}

En noviembre del año 2012 surgió una controversia en torno a la celebración de un matrimonio civil en el Ayuntamiento de Guardamar, provincia de Alicante. El diario Información lanzó el día 6 del citado mes el siguiente titular: «Polémica por la retirada de la foto del Rey en una boda por lo civil». La noticia hacía referencia al acto de descolgar, durante la celebración del matrimonio civil, la fotografía del Rey que preside el salón de plenos del ayuntamiento por petición de los contrayentes. El edil oficiante de la ceremonia declaró sobre esta decisión lo siguiente: "El concejal reitera que era conocedor de que la 
presencia de la foto del Jefe del Estado es preceptiva en actos institucionales, pero no necesariamente en actos de naturaleza privada como es una boda".

Dos años después de este suceso, El Consultor de los Ayuntamientos, revista técnica especializada en administración local y justicia municipal e indexada en Latindex, responde a la pregunta: ¿Se pueden celebrar bodas civiles en dependencias municipales que no tengan la bandera de España y el retrato del Rey? La respuesta de la revista se fundamenta en la siguiente normativa:

- El artículo 3.1. de la Ley 39/1981, de 28 de octubre, por la que se regula el uso de la bandera de España dispone que esta debe ondear en el exterior y ocupar lugar preferente en el interior de todos los edificios y establecimientos de la Administración central, institucional, autonómica provincial o insular y municipal del Estado. El término "lugar preferente» excluye la totalidad de las dependencias interiores y se entiende su colocación en espacios de alta representación de los ayuntamientos, como es el salón de plenos.

- El artículo 85 del Real Decreto 2568/1986, de 28 de noviembre, por el que se aprueba el Reglamento de Organización, Funcionamiento y Régimen Jurídico de las Entidades Locales, establece que la efigie del Rey se ubicará en lugar preferente del salón de sesiones.

La conclusión de El Consultor de los Ayuntamientos sobre la presencia de la bandera o el retrato del Rey en las ceremonias de los matrimonios civiles celebrados en los consistorios es: "Por todo lo anterior, entendemos que, si el local municipal de celebración de matrimonios civiles no fuese el salón de sesiones no habría obligación de colocar la bandera de España ni la efigie del Jefe del Estado.»

Estos antecedentes nos plantean la necesidad de determinar qué tipo de acto es la boda civil celebrada en el ayuntamiento y qué se define como tal.

Al ser el matrimonio civil un servicio de amplia proyección social que ofrece y ejecuta el ayuntamiento, consideramos la necesidad de enmarcar dentro del protocolo municipal el tipo de acto de que se trata. Para ello se recurre al del Real Decreto 2099/1983, de 4 de agosto, por el que se aprueba el Ordenamiento General de precedencias en el Estado, en donde clasifica los actos oficiales en general y especial.

Sobre esta división de los actos oficiales determinada por el Real Decreto son varios los expertos que analizan dicha clasificación. Destaca la ausencia de claridad en cuanto a la definición de los actos oficiales especiales, lo que origina la intención de su investigación con el objetivo de delimitar y afianzar el término de acto oficial especial. 
En conclusión, vamos a dar respuesta a las siguientes preguntas:

1. ¿Qué se entiende por acto oficial general?

2. ¿Qué se entiende por acto oficial especial?

3. ¿Qué tipo de acto es la ceremonia de matrimonio civil celebrada en los ayuntamientos?

\section{METODOLOGÍA}

Antes de afrontar la planificación de la investigación queremos indicar que esta se fundamenta en la afirmación de que "la investigación social estudia la realidad social, los hechos, actores, relaciones y acciones sociales desde una particular perspectiva: mediante la aplicación del método científico.» (Berganza y Sanz, 2010, p. 24).

La identificación de la celebración de la boda civil en el consistorio nos lleva a explorar una serie de términos relacionados con la cuestión como acto oficial, oficial general y oficial especial. El procedimiento elegido ha sido la investigación explorativa ya que esta "debe responder a un tema desconocido, poco estudiado o novedoso.» (Berganza y Sanz, 2010, p. 54). La investigación escogida ha sido la secundaria, es decir, "la elaborada a partir de datos recogidos por otros equipos investigadores en estudios previos." (Berganza y Sanz, 2010, p. 78). En este sentido, se ha acudido a las primeras firmas que sobre esta disciplina se encuentran en España: Carlos Fuente Lafuente, Francisco López-Nieto y Mallo, Francisco Marín Calahorro, Ma Teresa Otero Alvarado, Luis Fernando Ramos Fernández y Felio A. Vilarrubias Solanes.

\section{RESULTADOS}

A continuación analizamos los actos oficiales que tienen diferentes acepciones:

- Que es de oficio, o sea que tiene autenticidad y emana de la autoridad derivada del Estado, y no particular o privado. (Diccionario de la Lengua Española, 2001).

- Que procede del gobierno de la autoridad competente. 2. Dícese de aquello cuyo carácter auténtico o formal está públicamente reconocido por una autoridad. (Enciclopedia Universal Larousse, 2006, p. 4634).

- De las autoridades o del gobierno, o que tiene validez emanada de ellos. b) Que está reconocido por quien tiene autoridad para hacerlo. (Seco, Andrés y Ramos, 1999, p. 3274). 
Estas definiciones ponen el vocablo oficial en relación directa y dependiente con el término autoridad que hace referencia al "poder que gobierna o ejerce el mando, de hecho o de derecho» en su primera acepción recogida en el Diccionario de la Lengua Española, en donde se da como tercera acepción, «prestigio y crédito que se reconoce a una persona o institución por su legitimidad o por su calidad y competencia en alguna materia.» Para la Enciclopedia Universal Larousse (2006) autoridad es «poder político, administrativo o religioso", acepción número dos que complementa con la tercera, "persona que detenta cada uno de estos poderes.»

En referencia al acto oficial del Estado, en España se refiere a:

1. Los actos de la Corona:

El Rey es el Jefe del Estado, símbolo de su unidad y permanencia, arbitra y modera el funcionamiento regular de las instituciones, asume la más alta representación del Estado español en las relaciones internacionales, especialmente con las naciones de su comunidad histórica, y ejerce las funciones que le atribuyen expresamente la Constitución y las leyes. (Constitución Española, artículo 56.1).

2. Los actos de las Cortes Generales (poder legislativo):

Las Cortes Generales ejercen la potestad legislativa del Estado, aprueban sus Presupuestos, controlan la acción del Gobierno y tienen las demás competencias que les atribuya la Constitución. (Constitución Española, artículo 66.2).

3. Los actos del Gobierno y de la Administración (poder ejecutivo):

El Gobierno dirige la política interior y exterior, la Administración civil y militar y la defensa del Estado. Ejerce la función ejecutiva y la potestad reglamentaria de acuerdo con la Constitución y las leyes. (Constitución Española, artículo 97).

4. Los actos de los tribunales (poder judicial):

La justicia emana del pueblo y se administra en nombre del Rey por Jueces y Magistrados integrantes del Poder Judicial, independientes, inamovibles, responsables y sometidos únicamente al imperio de la ley. (Constitución Española, artículo 117.1).

En resumen, los actos oficiales serán los organizados por las autoridades de hecho o de derecho de estos cuatro poderes, y que Francisco López-Nieto lo denomina como la administración del protocolo oficial: «Designamos así al conjunto de órganos del Estado y de las demás Entidades públicas que tienen como misión cuidarse de programar, planificar, 
dirigir y realizar los actos públicos de la institución a la que sirven.» (López-Nieto, 2006, p. 41).

De manera genérica, Carlos Fuente Lafuente indica que los actos oficiales «serían aquéllos promovidos por las instituciones públicas del Estado o por sus representantes en el uso de dicha condición.» (Fuente, 2007, p. 84). A su vez, Carlos Fuente establece una clasificación de actos de la que destacamos, por su relación a lo tratado en estas líneas, los actos del Estado y explica que estos: "corresponden a los promovidos por la Jefatura del Estado y los tres poderes clásicos del Estado (Ejecutivo, Legislativo y Judicial), siempre que se ajusten a la naturaleza de los determinado en sus normativas sobre el carácter general de su convocatoria (en España actos de carácter general).» (Fuente, 2007, p. 87).

A continuación mostramos una tabla de clasificación de actos elaborada por María Teresa Otero Alvarado y presentada en las Jornadas de protocolo y relaciones institucionales organizadas por la Universidad Católica San Antonio de Murcia en el mes de marzo de 2012:

\begin{tabular}{|c|c|c|c|}
\hline \multicolumn{4}{|c|}{ Plantilla de modelo de variables (V) en la organización de eventos } \\
\hline $\begin{array}{c}\text { V. Independiente } 1: \\
\text { tipos de actos por titularidad }\end{array}$ & $\begin{array}{c}\text { V. Independiente } 2: \\
\text { territorialidad y competencias }\end{array}$ & $\begin{array}{l}\text { V. Independient 3: } \\
\text { tipología de asistentes }\end{array}$ & $\begin{array}{l}\text { Normativa } \\
\text { a aplicar }\end{array}$ \\
\hline V.D.1. Privadas & V.D.1. Privada & V.D.1. asistentes privados & Ninguna \\
\hline \multirow[b]{2}{*}{ V.D.2. Públicos no oficiales } & \multirow[b]{2}{*}{ V.D.2. Corporativa } & V.D.2. púlbico interno & normativa propia \\
\hline & & \begin{tabular}{|l} 
V.D.3. con autoridades \\
V.D.4. con personalidades
\end{tabular} & $\begin{array}{l}\text { normativa propia y } \\
\text { de organizaciones }\end{array}$ \\
\hline \multirow{6}{*}{$\begin{array}{c}\text { V.D.3. Oficiales } \\
\text { de carácter general }\end{array}$} & \multirow{4}{*}{$\begin{array}{l}\text { V.D.3. Poder ejecutivo y } \\
\text { administración central: } \\
\text { - Corona } \\
\text { - Gobierno } \\
\text { - Administración }\end{array}$} & V.D.3. solo autoridades & \begin{tabular}{|l} 
Real Decreto \\
(Art. 5.1.)
\end{tabular} \\
\hline & & V.D.3. con autoridades & Real Decreto \\
\hline & & V.D.4. con personalidades & (Art. 5.1.) \\
\hline & & & Normativa invitados \\
\hline & \multirow{2}{*}{$\begin{array}{l}\text { V.D.4. Poder ejecutivo de } \\
\text { las administraciones: } \\
\text { - CC.AA. } \\
\text { - Administración local: } \\
\text { - Ayuntamiento } \\
\text { - Diputación }\end{array}$} & V.D.3. solo autoridades & \begin{tabular}{|l} 
Real Decreto \\
Normativa propia \\
Tradición (Art. 5.2.)
\end{tabular} \\
\hline & & $\begin{array}{l}\text { V.D.3. con autoridades } \\
\text { V.D.4. con personalidades }\end{array}$ & $\begin{array}{l}\text { Real Decreto } \\
\text { Normativa propia } \\
\text { Tradición (Art. 5.2.) } \\
\text { Normativas invitados }\end{array}$ \\
\hline \multirow{2}{*}{$\begin{array}{c}\text { V.D.4. Oficiales } \\
\text { de carácter especial }\end{array}$} & \multirow{2}{*}{$\begin{array}{c}\text { V.D.5. Poder legislativo } \\
\text { Poder judicial }\end{array}$} & V.D.3. solo autoridades & $\begin{array}{l}\text { Normativa propia } \\
\text { Tradición } \\
\text { Real Decreto (Art. 6) }\end{array}$ \\
\hline & & $\begin{array}{l}\text { V.D.3. con autoridades } \\
\text { V.D.4. con personalidades }\end{array}$ & $\begin{array}{l}\text { Normativa propia } \\
\text { Tradición } \\
\text { Real Decreto (Art. 6) } \\
\text { Normativas invitados }\end{array}$ \\
\hline
\end{tabular}

Fuente: Otero Alvarado, 2012.

En esta tabla se puede comprobar que los actos oficiales son los organizados por los poderes del Estado y están regidos por la normativa oficial. 


\subsection{Clasificación de los actos oficiales del Estado}

Los actos oficiales son:

los organizados por el Estado en cualquiera de sus manifestaciones (central, autonómico o local en lo territorial y poderes ejecutivo, legislativo y judicial). (...) En los actos oficiales se convoca, organiza y financia a través de funciones y medios públicos, y por tanto la normativa debe ser expresamente clara y la rendición de cuentas ha de hacerse a la comunidad, auténtico origen y destino del evento. (Otero, 2005, p. 128).

A efectos de ordenar los actos oficiales, el Real Decreto 2099/1983, de 4 de agosto, por el que se aprueba el Ordenamiento General de precedencias en el Estado, establece la siguiente norma:

Artículo 3: A los efectos del presente Ordenamiento, los actos oficiales se clasifican en:

a) Actos de carácter general, que son todos aquellos que se organizan por la Corona, Gobierno y la Administración del Estado, Comunidades Autónomas o Corporaciones locales, con ocasión de conmemoraciones o acontecimientos nacionales, de las autonomías, provincias o locales.

b) Actos de carácter especial, que son los organizados por determinadas instituciones, organismos o autoridades, con ocasión de conmemoraciones o acontecimientos propios del ámbito específico de sus respectivos servicios, funciones y actividades.

Sobre esta división de los actos oficiales determinada por el Real Decreto 2099/1983, son varios los expertos que analizan dicha clasificación. Para Luis Fernando Ramos los actos generales están relacionados con acontecimientos que afectan a la comunidad, y los actos especiales están relacionados con su campo de actuación propio.

Actos generales son aquellos que conmemoran un acontecimiento que afectan al conjunto de la sociedad, ya sea en el ámbito nacional, autonómico, provincial o local. Actos especiales son aquellos que organizan las instituciones oficiales en el cometido de sus funciones. Estos últimos son los más habituales, siendo muy contados los primeros. De ahí la importancia de que las instituciones establezcan sus propias normativas al respecto. (Ramos, 2010, p. 130). 
Por su parte, Francisco López-Nieto indica que «los actos de carácter general son los más frecuentes y los que pueden suscitar mayor número de cuestiones.» (López-Nieto, 2006, p. $52)$.

Para Francisco Marín Calahorro la diferencia entre acto oficial general y especial «depende, esencialmente, de quien los organice y del ámbito en que se desarrolle la conmemoración o acontecimiento.» (Marín, 1997, p. 40). Sin embargo, existen ocasiones en las que es difícil clasificar como general o especial un acto atendiendo a lo articulado en el Real Decreto, tal y como explica Felio A. Vilarrubias: «El caballo de batalla en la aplicación del Real Decreto estriba en la delimitación de los actos, es decir, cuándo son generales o especiales, por cuanto existen circunstancias que, por su naturaleza, hacen difícil especificar su clase. Ante esta duda, debe optarse por clasificarlos como generales.» (Vilarrubias, 2004, p. 135).

En el ámbito municipal y en relación a lo legislado en referencia a los actos oficiales, Ignacio Martínez clasifica los actos municipales de la siguiente manera:

a) Actos de carácter general. Son todos aquellos que organiza institucionalmente la Corporación con ocasión de conmemoraciones o acontecimientos de gran importancia para la vida ciudadana municipal.

b) Actos de carácter especial. Son los organizados por las distintas áreas de actuación municipal con ocasión de conmemoraciones o acontecimientos propios del ámbito específico de sus respectivos servicios, funciones y actividades. (Martínez, 2006, p.167)

\subsubsection{Actos oficiales de carácter general}

Recordar que los actos oficiales del Estado de carácter general «son todos aquellos que se organizan por la Corona, Gobierno y la Administración del Estado, Comunidades Autónomas - Corporaciones locales, con ocasión de conmemoraciones o acontecimientos nacionales, de las autonomías, provincias o locales.» (Real Decreto 2099/1983, artículo 3).

Por lo tanto, los actos oficiales de carácter general son los organizados por:

1. La Corona. Para Felio A. Vilarrubias estos actos se denominan «de Corte» y "son los organizados por la Casa de S.M. el Rey en el Palacio Real o en la residencia que lo sustituya en virtud de las funciones propias de la Jefatura del Estado.» (Vilarrubias, 2004, p. 67).

2. La Administración del Estado «llamada a dirigir la programación y celebración de todos los actos públicos oficiales preeminentes de carácter nacional o internacional.» (López-Nieto, 2006, p. 41). 
3. La Administración Autonómica que «puede programar y ejecutar actos públicos, con arreglo a las normas de protocolo dimanentes del Estado, cuando en tales actos concurran autoridades de este último». (López-Nieto, 2006, p. 44).

4. La Administración local, haciendo referencia tanto a las Diputaciones provinciales como a los Ayuntamientos.

Y, siguiendo con la clasificación del Real Decreto, los actos oficiales de carácter general tienen como objetivo celebrar "conmemoraciones o acontecimientos nacionales, de las autonomías, provincias o locales.» (Real Decreto 2099/1983, artículo 3). Es decir, la finalidad de los actos oficiales de carácter general es conmemorar o celebrar hechos de relevancia para el territorio nacional, autonómico, provincial o local. Para Jacinto Cano de la Vega «titulamos de carácter general aquellos que tienen lugar con motivo de una efemérides nacional y en los que la invitación parte casi siempre de la primera Autoridad Civil o Militar.», (Cano de la Vega, 1965, p. 117).

\subsubsection{Actos oficiales de carácter especial}

Los actos oficiales de carácter especial «son los organizados por determinadas instituciones, organismos o autoridades, con ocasión de conmemoraciones o acontecimientos propios del ámbito específico de sus respectivos servicios, funciones y actividades.» (Real Decreto 2099/1983, artículo 3). O dicho de otro modo, los actos oficiales de carácter especial son los organizados por "las instituciones oficiales en el cometido de sus funciones", (Ramos, 2003, p. 80), para «dar solemnidad a un acto o conmemorar una fecha señalada de una rama de la Administración española.» (Cano de la Vega, 1965, p. 117).

Para Francisco Marín:

Será, precisamente, la acotación del acontecimiento, o conmemoración, como propio del ámbito específico de la institución, organismo o autoridades que lo organicen, lo que permita clasificar el acto diferenciándolo de otros, aunque puedan participar autoridades, personalidades y miembros de otras entidades del Estado no exclusivas del ámbito en que se desarrolle. (Marín, 1997, p. 50).

Para Francisco López-Nieto los actos oficiales de carácter especial «son los organizados por determinadas instituciones, organismos o autoridades». En referencia a esto, Francisco López-Nieto indica que los actos oficiales de carácter especial «podrían estar organizados por autoridades pertenecientes al ámbito judicial, al ámbito administrativo y al ámbito académico.» (López-Nieto, 2006, p. 73).

«En el ámbito judicial, los actos pueden estar organizados por el Consejo General del Poder Judicial o por los órganos de gobierno de los distintos tribunales.» (López-Nieto, 2006, p. 73). 
«En el ámbito administrativo deben destacarse dos instituciones como organizadores de actos: de un lado, el Consejo de Estado y, de otro, cualquier Departamento ministerial.» (López-Nieto, 2006, p. 73).

Estos actos se engloban dentro de los civiles, apuntados por Francisco Marín, quien añade los del ámbito del Poder legislativo, principalmente las dos Cámaras de las Cortes Generales, el Congreso y el Senado. Dentro del grupo de los actos oficiales civiles de carácter especial también se encuentran los "actos en el ámbito exclusivo de la organización administrativa de las Comunidades Autónomas.» (Marín, 1997, p. 53).

En relación al objetivo de los actos oficiales de carácter especial recordamos que se organizan «con ocasión de conmemoraciones o acontecimientos propios del ámbito específico de sus respectivos servicios, funciones y actividades.» (Real Decreto 2099/1983).

En el VII Congreso Internacional de investigación en Relaciones Públicas, Mạ Teresa Otero afirma que: "Actos públicos oficiales de carácter especial: están organizados por instituciones o autoridades que tanto Marín Calahorro (1997) como López Nieto (2000) como Otero $(2009,211)$ coinciden en identificar con los poderes legislativo y judicial en los niveles territoriales central y autonómico.» (Otero Alvarado, 2012, p. 265).

\subsection{El matrimonio civil}

La primera referencia normativa sobre el matrimonio civil en España data de 1870, año en el que se aprueba la Ley provisional de matrimonio civil: «Artículo 2. El matrimonio que no se celebre con arreglo a las disposiciones de esta ley, no producirá efectos civiles con respecto a las personas y bienes de los cónyuges y de sus descendientes.»

Esta forma de matrimonio es recogida posteriormente en el Código Civil del año 1889, concretamente en su artículo 42: "La Ley reconoce dos formas de matrimonio: el canónico, que deben contraer todos los que profesen la religión católica, y el civil, que se celebrará del modo que determina este Código.»

En la actualidad, el Código Civil en referencia a los matrimonios civiles dispone las siguientes normas:

Artículo 51: Será competente para autorizar el matrimonio:

1을 Juez encargado del Registro Civil.

20 En los municipios en que no resida dicho Juez, el Alcalde o el delegado designado reglamentariamente.

3o El funcionario diplomático o consular encargado del Registro Civil en el extranjero. 
Artículo 58: El Juez, Alcalde o funcionario, después de leídos los artículos 66, 67 y 68, preguntará a cada uno de los contrayentes si consienten en contraer matrimonio con el otro y si efectivamente lo contraen en dicho acto $y$, respondiendo ambos afirmativamente, declarará que los mismos quedan unidos en matrimonio y extenderá la inscripción o el acta correspondiente.

El artículo 51 es ampliado por la Orden JUS/577/2016, de 19 de abril, sobre la inscripción en el Registro Civil a través de la disposición transitoria única: «A partir del 30 de junio de 2017, (...), la tramitación del acta o expediente previo de capacidad matrimonial competerá al Notario, Letrado de la Administración de Justicia o Encargado del Registro Civil del lugar del domicilio de alguno de los contrayentes, con arreglo a I normativa del Registro Civil.»

El Real Decreto 2/2004, de 5 de marzo, por el que se aprueba el texto refundido de la Ley Reguladora de las Haciendas Locales aprueba con el artículo 20.5 que los «ayuntamientos podrán establecer una tasa para la celebración de los matrimonios en forma civil.»

En referencia a la logística, Julia Escamilla Rodríguez señala en su libro Organización y protocolo en las bodas que aquella se lleva a cabo por parte del departamento de protocolo del ayuntamiento o por la secretaría de alcaldía:

Hay consistorios que disponen de un gabinete de protocolo que se encarga de todo lo relacionado con la ceremonia y controla toda la tramitación de la documentación. También coordina fecha y hora del enlace y dispone de todos los recursos necesarios para que el acto se celebre según lo previsto.

Hay otros ayuntamientos que no disponen de este departamento y delegan esta función en la secretaría particular de la alcaldía. (...) Lo que se debe considerar es que cuentas con un servicio municipal que se encargue de todo lo relacionado con la celebración de las bodas. (Escamilla, 2005, p. 114)

Desde el punto de vista del protocolo, la boda civil es considerada como ceremonia familiar por parte de Francisco López-Nieto y Mallo en su publicación Manual de protocolo y señala que «se advierte que cada Alcaldía ha organizado la ceremonia en la forma que ha estimado más digna, y dentro de las disponibilidades municipales.» (López-Nieto, 2006, p. 461).

En opinión de Carlos Fuente Lafuente la boda es un acto social porque ha «dejado de ser, en definitiva, un acto familiar para convertirse probablemente en el más importante evento de carácter social existente en la actualidad.» (Fuentes, 2007, p. 337).

En relación al artículo 58 del Código Civil, Ignacio Martínez Suárez en su obra El protocolo en la administración local establece las fases de la ceremonia matrimonial civil sin determinar la clase de acto: 
1. La lectura de los preceptos del Código Civil que regulan los derechos y deberes de los cónyuges, que constituyen el objeto y el contenido del contrato.

2. La prestación del consentimiento por los contrayentes.

3. La declaración formal del funcionario autorizante constitutiva del matrimonio, y la fijación del acto en el soporte documental probatorio que supone la extensión y firma del acta. (Martínez, 2006, p. 157).

\section{DISCUSIÓN Y CONCLUSIONES}

Los actos oficiales del Estado se clasifican, por decreto, en generales y especiales. Los actos generales son aquellos organizados por la Corona y el poder ejecutivo y atienden a su ámbito territorial (nacional, autonómico, provincial o local). Los actos especiales son los organizados por las diferentes instituciones oficiales $y$ atienden a su propio ámbito (servicios, funciones, actividades).

Los actos oficiales de carácter general son aquellos organizados por la Corona, el Gobierno y la Administración (poder ejecutivo). Dichos actos tienen como objetivo conmemoraciones y acontecimientos de proyección territorial, es decir: nacional, autonómica, provincial o local.

En el caso de los actos oficiales especiales no encontramos una referencia clara sobre los mismos:

- Ma Teresa Otero considera acto oficial especial los organizados por el poder legislativo (Cortes Generales) y el judicial (tribunales).

- Francisco López-Nieto considera acto oficial especial los organizados por el poder legislativo, judicial, ejecutivo y académico.

- Francisco Marín considera acto oficial especial los organizados por el poder ejecutivo, legislativo y judicial.

Al respecto, queremos apuntar que gracias a las posturas de los diferentes expertos anotadas sobre esta cuestión, y a la información ofrecida, consideramos que:

- Los actos oficiales especiales son los organizados por el poder legislativo y judicial con ocasión de conmemoraciones o acontecimientos propios del ámbito específico de sus respectivos servicios, funciones y actividades.

- Son actos oficiales especiales los organizados por el poder ejecutivo, cuando sus actos oficiales se organizan con dicho objetivo, el de conmemorar o celebrar actos propios de su ámbito específico, y no «acontecimientos nacionales, de las 
autonomías, provincias o locales.» (Real Decreto 2099/83, art. 3). Estos son los actos oficiales de carácter general.

En referencia a la ceremonia del matrimonio civil en los ayuntamientos celebrada bajo las siguientes premisas se clasifica como acto oficial municipal:

- Convocada por el ayuntamiento: los servicios municipales autorizan el día y la hora de la celebración.

- Organizada por el consistorio: ya sea por el gabinete de protocolo o por secretaría de alcaldía, las bodas civiles en instancias municipales son dirigidas por dichas áreas.

- Financiada por la institución oficial: cuando los ayuntamientos no cobran tasas por este servicio municipal.

Delimitada la titularidad del acto del matrimonio civil como oficial, con sus características propias, ampliamos su carácter a especial ya que es organizada por determinados departamentos oficiales en respuesta a un servicio y función municipal concreta.

\section{REFERENCIAS}

Berganza Conde, Mạ Rosa, Ruiz San Román, José A. 2010, Investigar en comunicación, Mc Graw Hill, España.

Cano de la Vega, Jacinto. 1965, Tratado de protocolo, Ed. Gráficas Genovés.

Diccionario de la lengua española. http://www.rae.es/rae.html

Enciclopedia Universal Laorusse. 2006, Editorial Larousse.

Fuente Lafuente, Carlos, 2007, Manual práctico para la organización de eventos. Técnicas de organización de actos II, 3 a edición, ed. Protocolo, Madrid.

López-Nieto y Mallo, Francisco. 2006, Manual de protocolo, Ariel.

Martínez Suárez, Ignacio. 2006, El protocolo en la administración local, Ediciones Protocolo, Madrid.

Otero Alvarado, María Teresa. 2005, Los acontecimientos especiales como acciones de relaciones públicas: el ceremonial y el protocolo, Recuperado enero 20012 http://fama2.us.es/fco/digicomu/23.pdf 
Otero Alvarado, María Teresa. 2012, "Modelo de variables en la organización de eventos: una aportación a la aplicación de las normativas de protocolo y precedencias en las relaciones públicas organizacionales", Relaciones públicas: El diálogo de las organizaciones. VII Congreso internacional de investigación en Relaciones públicas. Sevilla, Facultad de Comunicación, 21-23 de marzo.

Ramos Fernández, Fernando. 2010, Comunicación y Protocolo en el espacio local. Elementos y técnicas para la transparencia y la imagen de las instituciones públicas, Servicio de Publicaciones de la Diputación de Pontevedra, Vigo.

Seco, Manuel, Andrés, Olimpia y Ramos Gabino. 1999, Diccionario del español actual, Aguilar, Madrid.

Vilarrubias Solanes, Felio A. 2004, Tratado de Protocolo, Ed. Nobel, Oviedo. 
(C) (7) 